\title{
El amor eficaz \\ como alternativa de resistencia democrática a la violencia neoliberal
}

\author{
Carlos Perea Sandoval \\ Universidad Santo Tomás de Aquino. Bucaramanga, Colombia \\ Email: carlos.perea@ustabuca.edu.co \\ Tania Meneses Cabrera \\ Universidad Nacional Abierta y a Distancia, Bogotá, Colombia \\ Email: tania.meneses@unad.edu.co
}

\begin{abstract}
Resumen $^{1}$ : El presente artículo de reflexión tiene como propósito realizar un análisis categorial de los discursos y las prácticas del modelo neoliberal y sus consecuencias en la dignidad humana, a través de una interpretación crítica de los documentos del Consenso de Washington y el informe OXFAM International 2107, principalmente. A partir de este análisis, se presentael amor eficazcomo una propuesta ético política legada por el Sociólogo Camilo Torres Restrepo, como una posibilidad de resistencia a las implicaciones de las políticas neoliberales en el contexto latinoamericano, desde un enfoque decolonial que concibe el territorio como una construcción histórico cultural.
\end{abstract} mocracia

Palabras claves: Neoliberalismo, análisis categorial, amor eficaz, de-

\section{Effective love as an alternative for democratic resistance to neoliberal violence}

\begin{abstract}
The purpose of this article is to make a categorical analysis of the discourses and practices of the neoliberal model and its consequences on human dignity, through a critical interpretation of the documents of the Washington Consensus and the 2017 OXFAM report, mainly. From this analysis, effective love is presented as a political ethical proposal passed on by the sociologist Camilo Torres Restrepo, as an option of resistance to the implications of neoliberal policies in the Latin American context, from a decolonized approach that understands the territory as a historical cultural construction.
\end{abstract}

Keywords: Neoliberalism, categorical analysis, effective love, democracy

\section{O amor eficaz como alternativa de resistência democrática à violencia neoliberal}

Resumo: O presente artigo de reflexão tem como propósito realizar uma análise categorial dos discursos e práticas do modelo neoliberal e suas consequências na dignidade humana, através de uma interpretação crítica dos documentos do 
Consenso de Washington e do informe OXFAM international 2107, principalmente. A partir dessa análise, se apresenta o amor eficaz como uma proposta ético política legada pelo Sociólogo Camilo Torres Restrepo, como uma possibilidade de resistência às implicações das políticas neoliberais no contexto latino-americano, desde um enfoque decolonial que concebe o território como uma construção histórico cultural. mocracia

Palavras chaves: Neoliberalismo, análise categorial, amor eficaz, de-

\section{Introducción}

El carácter prioritario que tiene el analizar las amenazas que se ciernen sobre las democracias en América Latina y los desafíos que éstas deben enfrentar a partir de una acción y construcción política amplia y participativa, permitirá superar las barreras históricas que han vivido las sociedades de la región, para dar paso a formas solidarias e inclusivas de actuar en democracia.

Con este propósito, el presente artículo propone el análisis categorial de los discursos y las prácticas del modelo neoliberal en América Latina, a partir de la aplicación de la Teoría del Cierre Categorial (TCC) expuesta por (Velarde 1992)como metodología para el análisis de los problemas propios de las ciencias sociales y humanas, identificando las relaciones establecidas a partir de la unión necesaria de los términos sin alterar la diversidad.

La metodología del cierre categorial ha sido trabajada por los autores en sus respectivas tesis doctorales (Perea 2011) acerca de las prácticas evaluativas de competencias ciudadanas y la construcción de subjetividades, desde un análisis socio jurídico y (Meneses 2016) acerca de un análisis de la política pública relacionada con la brecha digital de género, investigaciones donde se aplicó la TCC al análisis categorial del Modelo Neoliberal, identificando el campo de versores, entendido este como un sistema de enunciados que permiten identificar determinantes ideológicos.La estructura lógica, trasladada del campo de la geometría al campo las ciencias sociales, actúa de manera tal que una clase puede estar formada por el conjunto de los valores (dos en lógica bivalente; más de dos en lógica polivalente), y una clase p, por el conjunto de las variables (variables proposicionales, predicativas, etc.) que, a su vez, constituyen configuraciones de otras clases, como puede ser la clase de las funciones (funciones de un argumento, de dos, de tres, etc.), de suerte que las variables proposicionales vendrían ahora determinadas por las funciones de cero argumentos. (Velarde, 1992, p. 108).

Asimismo se utiliza para dicho análisis las derivaciones versoriales ficticias, definidas por los autores como juicios categoriales arbitrarios y el momento angular ideológico, entendido como el accionar de tres operado- 
res: los discursos, las prácticas y la imposiciones, para los cuales existe una condición lineal independiente, que son las leyes del mercado. En este sentido se evidencia la forma como el neoliberalismo toma como momento angular la separación entre la economía política y lo social, implicando un giro de transferencia del campo marcado por un proceso en el que la humanidad desde las leyes de humanidad se trasfiere a la inhumanidad desde la leyes del mercado.

Como respuesta alternativa a este modelo, se presenta el campo categorial del amor eficaz,conformado por losfuntores de resistencia y de transformación, entendiendo por funtorun operador que relaciona las categorías de territorio, economía y política, siguiendo los aportes teóricos de (Badiou, 2008, p. 311). La propuesta de amor eficaz fue desarrollada por el sociólogo colombiano y sacerdote revolucionario Camilo Torres Restrepo ${ }^{2}$, quien con su ejemplo permitió descifrar el espacio antropológico en el que el amor eficaz se hace realidad. Este espacio no es el normalizado por los dispositivos de poder impuestos por las políticas neoliberales sino un caosmosen el que es posible encontrar el humus cristiano.

\section{El territorio}

Introducimos el nombre de Abya Yala para denominar el territorio conocido como América Latina, siguiendo el enfoque de las teorías decoloniales (Porto-Gonçalves, 2009, p. 445) para hablar de un territorio que ha sido sistemáticamente agredido por las estructuras de poder imperialista, a través del uso de las violencias como medio para doblegar la dignidad de los pueblos y someterlos a un modelo económico propiciador de deshumanización. En este contexto, la historia de los pueblos de Abya Yala ha sido la historia de la resistencia y la biohumanidad. La resistencia ante los intentos colonizadores de usurpar el territorio, la naturaleza, los conocimientos, el cuerpo, el habla y nuestra existencia, tal como Sartre se lo hace conocer a los europeos en el prólogo del libro Los condenados de la tierra (Fanon, 1963).

"Sabéis que somos unos explotadores. Sabéis que nos hemos apoderado del oro y de los metales y el petróleo de los 'nuevos continentes' para traerlos a las viejas metrópolis. No sin excelentes resultados: palacios, catedrales, capitales industriales; y cuando amenazaba la crisis, ahí estaban los mercados coloniales para amortiguarla o desviarla. Europa, cargada de riquezas, otorgó de jure la humanidad a todos sus habitantes: un hombre, entre nosotros, quiere decir un cómplice puesto que todos nos hemos beneficiado de la explotación colonial. Ese continente rico y lívido acaba por caer en lo que Fanon llama justamente el «narcisismo». Cocteau se irritaba con $\mathrm{Pa}$ rís, 'esa ciudad que habla todo el tiempo de sí misma’. ¿Y qué otra cosa hace Europa? ¿Y ese monstruo supereuropeo, Norteamérica? Qué palabrería: libertad, igualdad, fraternidad, amor, honor, patria. ¿Qué se yo? Esto no nos impedía mantener al mismo tiempo un dis- 
curso racista: cochino negro, cochino judío, cochino moro”. (Fanon 1961: IV).

Estaresistencia acompasada con la biohumanidad se consolida como la condición ética que en estos territorios se construye a partir del respeto a la naturaleza y la convivencia equitativa con las demás formas de lo vivo no humano. La tensión economía deshumanizadora / biohumanidad es la que marca el sentido de la historia de nuestro puebloen tiempos de un modelo capitalista en crisis; tensión que configura un campo de versores ${ }^{3}$, con direcciones opuestas y magnitudes en desequilibrio:

El campo versorial de la economía deshumanizadora -configurado por los discursos y prácticas neoliberales y neoconservadoras-y el campo versorial de la biohumanidad -configuradopor la economía solidaria y el amor eficaz.- El neoliberalismo y el neoconservadurismo, toman como ángulo versorial, la separación entre la economía política y lo social implicando un giro de transferencia del campo, marcado por un proceso en el que la humanidad desde las leyes de humanidad se trasfiere a la inhumanidad desde la leyes del mercado.

"La idea fundamental es que, al transferir los problemas sociales al mercado, la solución y la satisfacción individual de las demandas y las necesidades permiten restablecer el principio de la responsabilidad individual. Al reemplazar el principio de responsabilidad colectiva por el de responsabilidad individual, se logra un mejor control de uno de los factores más desestabilizadores del sistema político y económico”. (Osorio 2006.p. 28).

\section{Análisis categorial del modelo neoliberal}

La magnitud y el ángulo vectorial de este modelo consolidan un módulo de acción de sujeción, que garantiza la imposición de políticas emanadas por organismos con carácter supravectorial, como el Banco Mundial (BM) y el Fondo Monetario Internacional (FMI), implicando un flujo de campo vectorial expresado en las políticas neoliberales -que se traduce en las condiciones impuestas por vectorsomas ${ }^{4}$ de valor absoluto como el llamado Consenso de Washington- de acuerdo con (Martínez y Soto2012: 37)“el Consenso de Washington presentó otro programa de ajuste estructural, después de Bretton Woods, para remediar los problemas derivados de la crisis de la deuda.

En esencia, dicho programa de ajuste fue diseñado para la región latinoamericana y después éste se hizo aplicable para cualquier región del mundo."

La matriz derivacional del vectorsoma absoluto seestructuró a partir de tres derivaciones vectoriales ficticias $(\mathrm{DVF})^{5}$ : 
1) El sector privado es más eficiente que el sector público.

2) Sólo si hay internacionalización habrá economía sustentable.

3) La distribución sólo es posible desde los polos de desarrollo.

La DVF1, crea un momento angular de imanología ${ }^{6}$; sustentado en dimensiones angulares como: Disminuir el Estado a su mínima expresión y trasladar la gestión social del Estado a la gestión mercantil del sector privado.

La DVF2, crea un momento angular de imanología II; sustentado en: Apertura de fronteras al capital y facilitar al máximo de inversión extranjera. La DVF3, crea un momento angular de imanología III; sustentado en: formalización de polos de desarrollo y distribución de riqueza entre los polos. A partir de las derivaciones versoriales ficticias se configura el momento angular ideológico que sustenta la política de sometimiento de los Estados a las leyes prefabricadas del mercado; estas leyes se sostienen en segmentos de interés configurando nuevos versores de derivación con las siguientes condiciones: disciplina fiscal, reordenación de las prioridades del gasto público, reforma fiscal, liberalización financiera, tipo de cambio competitivo, liberalización del comercio, liberalización de la inversión extranjera directa, privatizaciones, desregulación y derechos de propiedad. Un ejemplo de cómo actúa la base canónica de estas nuevas derivaciones versoriales es:

“A las variables políticas tradicionales (Estado, sistema político, ciudadanos), se agrega entonces una cuarta: el mercado. Se construye así un sistema de gobierno en el cual el Estado se vuelve independiente de la economía y protector del libre juego del mercado, que le asigna al sistema político un papel de administrador y de control de la acción del Estado. El mercado se transforma entonces en el campo de lo social, en el cual los intereses y las necesidades de las personas se detectan por sí mismas, ya que el mercado es el único mecanismo capaz de satisfacerlos. La acción social se concibe como la conducta de los ciudadanos individualizados que operan como consumidores; el Estado y el servicio público deben ofrecerles las mejores condiciones para canalizar sus demandas y sus necesidades". (Osorio 2006, p. 29).

Los vectorsomas que sustentan las políticas del Consenso de Washington tienen sus efectos en la red de generación de Humanidad en Humanidad para la Humanidad. Estos efectos se reflejan en el desequilibrio social, la degradación del Ser y la concentración de la riqueza, tal como se denuncia el informe OXFAM Internacional $2017^{7}$.

“Tan sólo 8 personas (8 hombres en realidad) poseen ya la misma riqueza que 3.600 millones de personas, la mitad más pobre de la humanidad. La súper concentración de riqueza sigue imparable. El crecimiento económico tan sólo está beneficiando a los que más tienen. El resto, la gran mayoría de ciudadanos de todo el mundo y 
especialmente los sectores más pobres, se están quedando al margen de la reactivación de la economía. El modelo económico y los principios que rigen su funcionamiento nos han llevado a esta situación que se ha vuelto extrema, insostenible e injusta. Es hora de plantear una alternativa. Necesitamos Gobiernos que apuesten por una visión de futuro y respondan ante su ciudadanía primero, grandes empresas que antepongan los intereses de trabajadores y productores, un crecimiento perpendicular a la dirección fija de L. El momento angular de una partícula sometida exclusivamente a una fuerza central es constante.dentro de los límites del planeta, el respeto de los derechos de las mujeres, y que el sistema fiscal sea justo y progresivo. Es posible avanzar hacia una economía más humana”. (Hardoon 2017, p. 11).

El paso de una red de Humanidad en Humanidad para la Humanidad a una red de Inhumanidad en inhumanidad para inhumanos, puede ser evidenciada en el informe OXFAM2017, en el cual se identifica una base canónica configurada con los siguientes versores de Inhumanidad (VDI):

VDI 1. Desde 2015, el 1\% más rico de la población mundial posee más riqueza que el resto del planeta.

VDI 2. Actualmente, ocho personas (ocho hombres en realidad) poseen la misma riqueza que 3.600 millones de personas (la mitad de la humanidad).

VDI 3. Durante los próximos 20 años, 500 personas legarán 2,1 billones de dólares a sus herederos, una suma que supera el PIB de la India, un país con una población de 1.300 millones de personas.

VDI 4. Los ingresos del 10\% más pobre de la población mundial han aumentado menos de 3 dólares al año entre 1988 y 2011, mientras que los del 1\% más rico se han incrementado 182 veces más.

La combinatoria de los versores (VDI) implica la generación de una matriz de inhumanidad, estructurada a partir de nuevas derivaciones vectoriales ficticias (DVF).

DVF 4. El mercado nunca se equivoca, y hay que minimizar el papel de los Gobiernos.

DVF 5. Las empresas tienen que maximizar sus beneficios y la rentabilidad de los accionistas a toda costa.

DVF 6. La riqueza individual extrema no es perjudicial sino síntoma de éxito, y la desigualdad no es relevante.

DVF 7. El crecimiento del PIB debe ser el principal objetivo de la elaboración de políticas.

DVF 8. Nuestro modelo económico es neutral desde el punto de vista del género

DVF 9. Los recursos de nuestro planeta son ilimitados.

Las DVF impulsan la diáspora de un Momento Angular Ideológico 
(MAI) que sustenta la concentración de la riqueza y la desigualdad, en un marco de ilegalidad tal como lo referencia (Colussi2002)

"El capitalismo contemporáneo, manejado por mega-capitales de alcance planetario, se asemeja más a una estructura mafiosa, corrupta y delincuencial que al espíritu empresarial que lo puso en marcha hace ya algunos siglos. La "aventura" de invertir y buscar hacer prosperar el negocio, sabiendo que ello puede suceder pero que no está asegurado de antemano -el riesgo ocupaba un lugar por ciertose cambió hoy día por un esquema donde la ganancia fácil es la norma. Para ello este nuevo esquema corrupto se asegura su "éxito" con prácticas más de orden criminal que empresarial.

Estados Unidos requiere libertad de acción en las zonas comunes globales y acceso estratégico a regiones importantes del mundo para satisfacer nuestras necesidades de seguridad nacional”, puede leerse en la Estrategia de Defensa Nacional de Washington del año 2008. La ganancia se asegura al precio que sea, y si es por medio de la fuerza bruta, no importa: el fin justifica los medios. La proclamada "libre competencia" quedó en la historia. El mundo pasó a ser el campo de acción de bandas delincuenciales... ¡legales!, con poderes omnímodos y que se dan el lujo de hablar de democracia y libertad. Igual que un gánster de barrio, el actual capitalismo se mueve con la más descarada bravuconería e impunidad”. (Colussi 2002, p.53).

Las relaciones sinérgicas establecidas por el MAI produce sus efectos en la degradación de la condición de humanidad, efectos denunciados en el informe OXFAM 2017.

"Es innegable que el modelo de economía globalizada ha beneficiado principalmente a las personas más ricas. Varias investigaciones de OXFAM revelan que, en los últimos 25 años, el 1\% más rico de la población ha percibido más ingresos que el 50\% más pobre de la población en su conjunto. Lejos de transmitirse espontáneamente hacia abajo (en la llamada "economía de goteo o de derrame), los ingresos y la riqueza se vuelcan hacia las capas más altas de la sociedad, y lo hacen a un ritmo alarmante. ¿Cuál es la causa? Las grandes empresas y el poder de los más ricos desempeñan un papel esencial” (Hardoon 2017, p.3).

El modelo categorial del Neoliberalismo y Neoconservadurismo expuesto, se debe asumir como productos históricos generados por una élite que logró, aplicando la violencia, un poder político y económico legitimado en la estructuración y funcionamiento del Estado; por ser producto histórico el modelo hegemónico está expuesto a las dinámicas de transformación y resistencia desde el campo del amor eficaz. 


\section{Campo categorial del amor eficaz}

"No se trata de buscar respuestas en Camilo, sino de compartir sus preguntas. Preguntas que no se realizaron desde el lugar de la contemplación, sino de manera activa. Preguntando con los cuerpos. Preguntando con sus vidas. Preguntando con sus ejemplos. Preguntando, como una manera de abrir caminos”. (Korol, Peña, 2010, p.13)

Como resistencia al neoliberalismo surge el amor eficaz como nuevo campo categorial en el cual pierde legitimidad el campo de versores sobre el que se edificó la política y acción neoliberal. Este amor eficazfue propuesto por el sacerdote colombiano Camilo Torres Restrepo, en el mensaje a los cristianos:

"Lo principal en el catolicismo es el amor al prójimo. "El que ama a su prójimo cumple con la ley” (San Pablo, Rom. XIII. 8). Este amor para que sea verdadero tiene que buscar la eficacia. Si la beneficencia, la limosna, las pocas escuelas gratuitas, los pocos planes de vivienda, lo que se ha llamado "la caridad", no alcanza a dar de comer a la mayoría de los desnudos, ni a enseñar a la mayoría de los que no saben, tenemos que buscar medios eficaces para el bienestar de las mayorías”. (Torres, 1970, p. 26).

Tal como sostiene Perea(2016) el amor eficaz es la expresión moral que guía la acción de los humanos como generadores de humanidad. Este amor es ecuménico y pan-ético. Su condición rompe con el antropocentrismo e incluye una bioarmonía (el apoyo mutuo entre lo vivo humano y lo vivo no humano), que se dinamiza en el caosmo- amar como el escenario natural de la ocio-felicidad y la paz.

El campo categorial del amor eficaz se estructura a partir de los Funtores $^{8}$ de Resistencia FR1 (contra el Trabajo enajenado) y FR2 (contra la Democracia hegemónica.)

\section{Primer Funtor (FR1): Contra el Trabajo enajenado}

En FR1 se anulan las derivaciones vectoriales ficticias ligadas al trabajo y el empleo y se derivan nuevos vectores de veracidad (NVV)

- NVV1. El trabajo es externo y niega al trabajador

- NVV2. El trabajo es autosacrificio y arruina el espíritu

Estos vectores de veracidad se pueden identificar en el análisis del trabajo enajenado realizado por K. Marx: 
“¿En qué consiste, entonces, la enajenación del trabajo? Primeramente en que el trabajo es externo al trabajador, es decir, no pertenece a su ser; en que en su trabajo, el trabajador no se afirma, sino que se niega; no se siente feliz, sino desgraciado; no desarrolla una libre energía física y espiritual, sino que mortifica su cuerpo y arruina su espíritu. Por eso el trabajador sólo se siente en sí fuera del trabajo, y en el trabajo fuera de sí. Está en lo suyo cuando no trabaja y cuando trabaja no está en lo suyo. Su trabajo no es, así, voluntario, sino forzado, trabajo forzado. Por eso no es la satisfacción de una necesidad, sino solamente un medio para satisfacer las necesidades fuera del trabajo. Su carácter extraño se evidencia claramente en el hecho de que tan pronto como no existe una coacción física o de cualquier otro tipo se huye del trabajo como de la peste. El trabajo externo, el trabajo en que el hombre se enajena, es un trabajo de auto sacrificio, de ascetismo. En último término, para el trabajador se muestra la exterioridad del trabajo en que éste no es suyo, sino de otro, que no le pertenece; en que cuando está en él no se pertenece a sí mismo, sino a otro. Así como en la religión la actividad propia de la fantasía humana, de la mente y del corazón humano, actúa sobre el individuo independientemente de él, es decir, como una actividad extraña, divina o diabólica, así también la actividad del trabajador no es su propia actividad. Pertenece a otro, es la pérdida de sí mismo. De esto resulta que el hombre (el trabajador) sólo se siente libre en sus funciones animales, en el comer, beber, engendrar, y todo lo más en aquello que toca a la habitación y al atavío, y en cambio en sus funciones humanas se siente como animal. Lo animal se convierte en lo humano y lo humano en lo animal. (Marx, 2006, p.76)

FR1 como condición histórica, propicia el emerger de las categorías de módulos: (CM1 Y CM2)

\section{- CM1. El trabajo asalariado es innecesario}

Las políticas neoliberales, junto con el avance de la ciencia y la tecnología, son factores que inciden determinantemente en el hecho histórico de la disolución del trabajo.

"Vivimos en medio de una falacia descomunal: un mundo desaparecido que nos empeñamos en no reconocer como tal y que se pretende perpetuar mediante políticas artificiales. Millones de destinos son destruidos, aniquilados por este anacronismo debido a estratagemas pertinaces destinadas a mantener con vida para siempre nuestro tabú más sagrado: el trabajo”. (Forrester 1997, p. 2)

\section{- CM2. El empleo no es una virtud}

Asistimos en un tiempo en el que el empleo no es una virtud, sino una categoría económica efímera. El empleo creó el espejismo en el que la humanidad trató de ser humanidad. 
"En la actualidad, un desempleado no es objeto de una marginación transitoria, ocasional, que sólo afecta a determinados sectores; está atrapado por una implosión general, un fenómeno comparable con esos maremotos, huracanes o tornados que no respetan a nadie y a quien nadie puede resistir. Es víctima de una lógica planetaria que supone la supresión de lo que se llama trabajo, es decir, de los puestos de trabajo. Pero aún hoy se pretende que lo social y económico está regidos por las transacciones realizadas a partir del trabajo cuando éste ha dejado de existir. Las consecuencias de este desfasaje son crueles. Se trata y se juzga a los sin trabajo, víctimas de esa desaparición, en función de los criterios propios de la época en que abundaban los puestos de trabajo. Despojados de empleo, se los culpa por ello, se los engaña y tranquiliza con promesas falsas que anuncian el retorno próximo de la abundancia, la mejoría rápida de la coyuntura afectada por los contratiempos”. (Forrester, 1997, p.6)

\title{
Segundo Funtor (FR2). Contra la democracia hegemónica
}

Camilo Torres, en su condición de sacerdote y sociólogo denunció las falacias de la democracia, a partir de juicios categóricos como: -las vías legales están agotadas- y -el que escrute elige-. Para Camilo la verdadera democracia debía nacer del pueblo, ser con el pueblo y para el pueblo. Esta visión de la democracia está también en el pensamiento de Gramsci, tal como lo reseña (Rodríguez, Seco 2007: 18).

\begin{abstract}
“Creemos que la idea de posibilidad democrática se obtiene de una comprensión abierta de democracia. A esto hay que decir que la democracia no es ese ente abstracto o metafísico, no es un proyecto acabado y cerrado, que permite obstinarnos en defender unas instituciones suficientemente malogradas por las abstracción individualista, y como diría el propio Gramsci, capitalista. La democracia no consiste en esto. Ni se abstiene, ni se aleja de las plazuelas o las calles. La democracia es una práctica que nada más ni nada menos que sobre la acción común, el trabajo común y la construcción común de nuevas posibilidades. Es una práctica abierta a nuevas posibilidades capaces de introducir la idea de autogobierno y el respeto a las singularidades que conforman el colectivo. (Rodríguez, Seco, 2007, p. 18)
\end{abstract}

El accionar de FR2 propicia el emerger de las categorías de módulos: (CM3 y CM4)

\section{- CM3. La falsa democracia}

En términos de la filosofía política se presenta la viabilidad de considerar la democracia como una construcción de la irrealidad y por lo tanto la democracia es un artificio de dispositivos de poder para generar subjetivi- 
dades ciudadanas normalizadas y sujetas con el fin de ser reproductoras de un sistema propio de la democracia liberal burguesa. La producción biopolítica de una subjetividad para el mercado está direccionada por las prácticas capitalistas en términos de derechos y deberes, propios de una subjetividad jurídica, que a su vez configuran un sujeto ciudadano desde una red institucional y desde un marco jurídico preestablecido(Perea, 2011, p.127).Las luchas por el reconocimiento de la demodiversidad implican denunciar las limitaciones de la democracia liberal, que se ha revelado un sistema político ineficiente, opaco, reproductor de desigualdades, subordinado a intereses privados y sostenido, en buena medida, por la corrupción, el conformismo y la apatía. (Bonet, 2017, p. 32).

\section{- CM4. La democracia secuestrada}

Constreñir la democracia consiste en la práctica de la gubernamentalidad, que mediante dispositivos de poder propician la subordinación del modelo de desarrollo social al modelo del mercado, proceso propio del modo de producción capitalista sustentando en la ideología económica del capital y la política liberal burguesa. Los modelos autollamados democráticos funcionan en la paradoja de secuestrar la democracia, acción delincuencial contra la dignidad humana, liderada y ejecutada por los milmillonarios del planeta; el 1\% de la población tiene secuestrada y extorsionada al 99\% a partir de la corrupción y amparados en organismos supravectoriales como el BM, el FMI y la OCDEC que actúan como carteles, tal como se denuncia en el informe OXFAM 2017.

"Los súper ricos están interesados en promover políticas que favorezcan la acumulación de su riqueza, por encima de otras que tengan un impacto más redistributivo en la sociedad; los estudios han concluido que se benefician de que la distribución de la riqueza sea más desigual, y que por lo tanto intentarán utilizar su influencia para proteger estos intereses. Donella Meadows lo explica argumentando que los ricos refuerzan un "círculo vicioso que se retroalimenta" y en el que los grandes ganadores obtienen aún mayores rentabilidades y privilegios que a su vez les permiten obtener beneficios cada vez mayores. Por ejemplo, utilizan su riqueza para respaldar a candidatos políticos, financiar acciones de lobby y, de manera más indirecta, dotar de fondos a centros de estudios y universidades para que orienten las narrativas políticas y económicas en defensa de una serie de falsas premisas que favorecen a los más ricos. En Brasil, los milmillonarios hacen lobby para conseguir una bajada de impuestos, y en Sao Paulo prefieren desplazarse en helicóptero, sobrevolando los atascos y las infraestructuras en mal estado que se extienden a sus pies. En Estados Unidos, los hermanos Koch, dos de los hombres más ricos del mundo, han ejercido una considerable influencia en el sector conservador de la política estadounidense, apoyando a muchos centros de estudio influyentes como el Instituto Cato y al movimiento Tea Party, además de contribuir enormemente a 
desacreditar los argumentos en favor de la necesidad de tomar medidas contra el cambio climático. Los hermanos Gupta, de origen indio, son dos hombres de negocios que mantienen una estrecha relación con el Presidente de Sudáfrica Jacob Zuma, sobre quien presuntamente ejercen una influencia indebida”. (Hardoon, 2017, p. 25).

Este secuestro de la democracia invita a realizar una reflexión crítica con preguntas como las formuladas por(Rodríguez1996:56). Acerca de si pueden reconciliarse las exigencias de una vida pública democrática (debate abierto, acceso a los centros de poder, participación general) con aquellas instituciones del estado (desde el ejecutivo hasta las ramas de la administración) que florecen en el secreto y control de los medios de coerción; desarrollando sus propios intereses e insensibles a las demandas del demos. El análisis categorial desarrollado genera un producto tensorial concretado en el amor eficaz, cuyo horizonte se sostiene en la exigencia de construir una nueva modalidad de acción para que el ser humano encuentre en la solidaridad social y en la capacidad de dirección personal, el camino que sustenta la existencia.El producto tensorial, en el pensamiento y accionar político de Camilo Torres, está sustentado en los Funtores de Transformación (FT), tal como se exponen:

FT1. El ecumenismo pan-ético: Camilo Torres como militante del amor eficaz, siempre concibió al humano en humanidad. Su llamado pastoral exigía una fuerte unión entre el clero y el pueblo; entre la profesión de la fe y la construcción de un mundo militante de lo moral como anticipación del paraíso. Este modelo de ecumenismo debe asumirse hoy como una propuesta organizativa para enfrentar el individualismo y la competencia proyectada en el modelo neoliberal.

FT2. La bio-armonía: implica comprender la responsabilidad de lo humano en la conservación del bios, que en el discurso de Camilo se entendía en el sentido de como Dios hizo al hombre no para dominar la naturaleza, sino para amarla. Palabras que el papa Francisco recalca en la encíclica papal Laudato Sí.

“Posiblemente nos inquieta saber de la extinción de un mamífero o de un ave, por su mayor visibilidad. Pero para el buen funcionamiento de los ecosistemas también son necesarios los hongos, las algas, los gusanos, los insectos, los reptiles y la innumerable variedad de microorganismos. Algunas especies poco numerosas, que suelen pasar desapercibidas, juegan un rol crítico fundamental para estabilizar el equilibrio de un lugar. Es verdad que el ser humano debe intervenir cuando un geo sistema entra en estado crítico, pero hoy el nivel de intervención humana en una realidad tan compleja como la naturaleza es tal, que los constantes desastres que el ser humano ocasiona provocan una nueva intervención suya, de tal modo que la actividad humana se hace omnipresente, con todos los riesgos que esto implica”. (Francesco, 2015, p. 26). 
Pero para hacer andar esta moral se requiere tener una conciencia crítica, entendida como el darnos cuenta de nuestra propia condición, que necesariamente implica la generación de transformaciones en una dialéctica de construir - destruyendo. En palabras de Camilo Torres: "La revolución no solamente es permitida sino obligatoria para los cristianos que vean en ella la única manera eficaz y amplia de realizar el amor para todos."

FT3. El caosmo- amar: Camilo fue un sacerdote que con su ejemplo permitió descifrar el espacio antropológico en el que el amor eficaz se hace realidad. Este espacio no es el normalizado por dispositivos de poder, sino un caosmos en el que es posible encontrar el "humus cristiano". Al respecto Monseñor Darío de Jesús Monsalve refiriéndose al pensamiento de Camilo, afirma:

"La lucha de Camilo se arraiga en el humus cristiano: más que en lo ideológico, en la experiencia popular; más que en la lucha de clases, en la unidad como principio ético de toda acción transformadora colectiva y en el aprendizaje y la pedagogía desde el mundo de los pobres. Camilo se vuelve ahora una figura 'puente' y un jalón hacia el reencuentro más posible entre orillas opuestas; una conexión entre el evangelio social de la Iglesia de ayer y la que emerge hoy, impulsada por la figura y el mensaje "revolucionario" del papa Francisco. (Arias, 2016, p.26)

\section{FT4. La ocio-felicidad en la paz:}

Camilo Torres como sacerdote y revolucionario, denunció el accionar del modelo de explotación capitalista en cuanto a las limitaciones que impuso respecto al derecho al descanso y la vivencia lúdica; propuso que era un deber de todo militante de la vida el luchar para construir la paz como un espacio de libertad y vivencia de la ocio- felicidad, en una dinámica de cambio y transgresión.

“...el ocio puede a su vez llegar a generar una experiencia de apertura marcada por una actitud que rompa y transgreda con lo permitido y con lo lícito, mostrándose muchas veces al borde de lo socialmente adecuado y aceptado. Justamente a esto se debe uno de los grandes temores, así como peligros que representa el ocio para el mantenimiento del "status quo". De aquí surge, en parte, el intento de acallar y prohibir la disruptividad, contracorriente, alteridad e innovación subversiva, y todo aquello que pueden expresar un ocio creativo, caótico y transformacional”. (Elizalde, 2010, p. 445). 


\section{Conclusión}

En el caso de Colombia y de toda la América Latina -porque yo creo que la lucha va a ser conjunta- los enemigos de nuestros enemigos serán nuestros amigos. Pero cuando el pueblo se decida a luchar hasta el fin no habrá ninguna potencia que pueda ser superior a la potencia de ese pueblo que quiere su libertad. Reportaje de Jean-Pierre Sergent, 1965.

(Korol Peña, 2010, p. 89)

El camino ocio-felicidad en código de paz, requiere de un compromiso efectivo desde cada uno de los campos de accionar de nuestras vidas, para enfrentar la injustica. Camilo Torres representa el compromiso desde todas las dimensiones de su vida: como cristiano en la búsqueda del amor eficaz; como político en el esfuerzo de darse "hasta las últimas consecuencias"; como científico, en el propósito de buscar "los propios caminos" de la ciencia. Como militante del Amor Eficaz, siempre concibió al humano en humanidad, su llamado pastoral exigía una fuerte unión entre el clero y el pueblo; entre la profesión de la fe y la construcción de un mundo militante de lo moral como anticipación del paraíso: la ocio -felicidad en paz. El amor eficaz, se consolida como la opción moral de resistencia democrática a la agresión del modelo neoliberal. Es importante, por lo tanto, asumir el compromiso con la humanidad en humanidad como una vía para desmontar la estructura categorial del Neoliberalismo y el Neoconservadurismo, que se quiere imponer desde una visión política y económica de carácter fascista. Es imperativo entonces resistir. "Afirmar que la utopía(lo que no tiene lugar) se volvió eutopía(un lugar bueno), que nuestro futuro es la transfiguración del universo y de todo lo que él contiene, especialmente la vida humana, y no polvo cósmico. Tal vez sea esta nuestra gran esperanza, nuestro futuro absoluto”. (Boff, 1996, p. 96). 


\section{Notas}

${ }^{1}$ Este artículo es producto de las reflexiones pedagógicas para el programa de Sociología de la UNAD y el campo de formación en Humanidades en la Universidad Santo Tomas de Aquino

${ }^{2}$ La labor de Camilo Torres Restrepo como académico, sacerdote y capellán de la Universidad Nacional de Colombia le permitió el estudio y promoción de las reformas del concilio Vaticano II, se preocupó por interiorizar en el pueblo la idea de que "el deber de todo cristiano no era rezar más niño amar más.” Camilo fue perseguido por la oligarquía y el clero colombiano, lo que aceleró, desde una convicción política, el ingreso al Ejército de Liberación Nacional (ELN). El 15 de Febrero de 1996 fue abatido en combate con las tropas oficiales, en Patio Cemento (Santander, Colombia).

${ }^{3}$ El versor es definido por los autores como un sistema de enunciados que permiten identificar determinantes ideológicos. El versor es un elemento que gira alrededor de un punto fijo con una determinada velocidad angular. En el campo de la física a un vector de valor 1 se le denomina versor. Los versos son una modelación algebraica de las rotaciones.

${ }^{4}$ El vectorsoma es una derivación del versor propuesta por los autores como operador para el análisis de los problemas de las ciencias sociales. Implica el devenir histórico de instituciones que han tendido a considerarse absolutas.

${ }^{5}$ Las Derivaciones Vectoriales Ficticias (DVF) son definidas por los autores como juicios categoriales arbitrarios. Tomado de la lógica se atribuye a una materialidad discursiva que no admite discusión.

${ }^{6}$ Para los autores el Momento angular de imanología es entendido como el accionar de tres operadores: los discursos, las prácticas y la imposiciones, para los cuales existe una condición lineal independiente: las leyes del mercado). Este conceptose construye a partir de la física en la que el momento angular L de una partícula es el vector producto vectorial $\mathrm{L}=\mathrm{r}$ xmv, perpendicular al plano determinado por el vector posición $\mathrm{r}$ y el vector velocidad $\mathrm{v}$. Como el vector L permanece constante en dirección, $\mathrm{r}$ y v estarán en un plano

${ }^{7}$ OXFAM International, es una confederación internacional de 20 organizaciones que trabajan junto a organizaciones socias y comunidades locales en más de 90 países. Trabaja proporcionando ayuda de emergencia, llevando a cabo proyectos de desarrollo a largo plazo y haciendo campaña por un futuro más justo. https://www.oxfam.org/es/ quienes-somos

${ }^{8}$ Se asume el funtor como el operador que relaciona las categorías de territorio, economía y política. En la lógica formal el funtor es un operador lógico, cuyo contenido semántico es nulo, a partir del cual se establecen relaciones entre enunciados. "En teoría de categorías un funtor es una función de una categoría a otra que lleva objetos a objetos y morfismos a morfismos de manera que la composición de morfismo e identidades se preservan.” "El año de 1955 Grothendiek escribe el tratado sobre las categorías abelianas donde aparece la noción de teoría de categorías como un tema propio de estudio y allí surge la serie de funtores derivados de funtores de módulos.” (Lecturas matemáticas, p.93) http://www.scm.org.co/aplicaciones/revista/Articulos/1159.pdf 


\section{Bibliografía}

Arias, D. (2016). Camilo Torres se la jugaría por el desmonte de violencia insurgente. Monseñor Darío de Jesús Monsalve habla de la paz y la importancia de la ideología del sacerdote. El Tiempo. Entrevista. 27 de enero 2016. Recuperado de http://www.eltiempo.com/archivo/ documento/CMS-16492951

Badiou, A. (2008). Lógicas de los mundos: el ser y el acontecimiento.Buenos Aires, Argentina: Ediciones Manantial.

Boff, L. (1996). Ecología: grito de la tierra, grito de los pobres. Madrid. España: Editorial Trotta.

Bonet, A. (2017). Descolonizar la democracia: apuntes sobre demodiversidad y nuevo constitucionalismo en Bolivia. Astrolabio: Revista internacional de filosofía, (19) 26-36

Colussi, M. (2002). Movimientos indígenas latinoamericanos: un desafío. Sembrando utopía Crisis del capitalismo y refundación de la Humanidad, 157. Recuperado dehttp://www.albedrio.org/htm/documentos/ vvaaSembrandoutopia.pdf\#page $=161$

Elizalde, R. (2010). Resignificación del ocio: aportes para un aprendizaje transformacional. Polis.Revista Latinoamericana, 9 (25) 437-460. Recuperado de https://polis.revues.org/642

Fanon, F. (1963). Los condenados de la tierra. México, DF, México: Fondo de Cultura Económica.

Farfán, N. y Guzmán, L. (2013). ReseñaCiencia, compromiso y cambio social. Orlando Fals Borda. Antología de Nicolás Armando Herrera Farfán. Utopía y Praxis Latinoamericana, 18(62), 167-172.

Francesco, P. (2015). Laudato SI. Roma, Italia: Edizioni piemme.

Forrester, V. (1997). El horror económico.México D.F., México:Fondo de Cultura Económica.

Hardoon, D. (2017). Informe Oxfam. Oxfam Internacional. Oxford, OX4 2JY, UK.

Korol, C., Peña, K., Herrera, N. (comp) (2010). Camilo Torres. El amor eficaz. Buenos Aires, Argentina: América Libre.

Levine, D. (2011). Camilo Torres: fe, política y violencia. Sociedad y religión(21), 34-35

Lombraña, J. (1992). Teoría del cierre categorial aplicado a las matemáticas. 
La filosofía de Gustavo Bueno. Revista Meta, 105- 126. Recuperado de http://www.fgbueno.es/med/dig/meta89e.pdf

Martínez, R., Garmendia, R., y Soto, E. (2012). El Consenso de Washington: la instauración de las políticas neoliberales en América Latina. Política y cultura, (37) 35-64

Marx, K. (2006). Manuscritos: economía y filosofía(1844). Buenos Aires, Argentina: Colihue.

Meneses, T. (2016). Sujeto mujer y brecha digital de género. Discursos y prácticas desde la gubernamentalidad en América Latina (Tesis Doctorado). Universidad de Artes y Ciencias Sociales, Santiago, Chile.

Ocampo, J. (1998). Más allá del Consenso de Washington: una visión desde la CEPAL. Revista de la CEPAL, (66), 7-28.

Ídem, (2006). Más allá del Consenso de Washington. Economía UNAM, 3(7), 07-25.

Osorio, R. (2006). Los principios del modelo neoconservador de gobernabilidad aplicado en América Latina durante los’ 90 (Translated by Silvina Cucchi). Nueva Sociedad (205) 23-29. Recuperado de http://nuso.org/media/articles/downloads/3378_1.pdf

Parker, C. (1993). Otra lógica en América Latina: religión popular y modernización capitalista. Santiago, Chile: Fondo de Cultura económica.

Perea, C. (2016). El amor eficaz como alternativa ética para el posconflicto. Revista DOXA (44).

Ídem. (2011). Las prácticas evaluativas de competencias ciudadanas y la construcción de subjetividades, desde un análisis socio jurídico (Tesis Doctorado) en Universidad Externado de Colombia, Bogotá, Colombia.

Porto-Gonçalves, C. W. (2009). Del desarrollo a la autonomía: la reinvención de los territorios. Revista América Latina en Movimiento, 445. Recuperado de http://www.alainet.org/es

Rodríguez, R., y Seco, J. M. (2007). Hegemonía y Democracia en el siglo XXI. XXI Jornadas de la Sociedad Española de Filosofía Jurídica y Política, Problemas actuales de la Filosofía del Derecho, Madrid, España.

Rodríguez, X. (1996). La democracia hegemónica, ¿hhegemonía de la democracia? Revista mexicana de ciencias políticas y sociales, 41(164). 
Polis, Revista Latinoamericana, Volumen 16, $N^{\circ}$ 46, 2017

Torres, C. (1965). Mensaje a Los Cristianos (1), agosto 26 de 1965, pág. 3. Periódico Frente Unido. Bogotá. https://www.marxists.org/espanol/ camilo/cristianos.htm

Torres, C. (1970). Cristianismo y revolución. Bogotá, Colombia: Ediciones Era.

Recibido : 15.03 .17

Aceptado 15.04.17 